Copyright 1915 . By A. I. E. E.

\title{
THE TREND OF ELECTRICAL DEVELOPMENT President's Address
}

\author{
BY PAUL M. LINCOLN
}

$\mathrm{N}$ ANNUAL address by the president of our Institute is
more than a perfunctory affair. It is a constitutional requirement. It is enumerated specifically in our constitution among the duties of the president-" He shall deliver an address at the annual convention."

It has occurred to me that in my address on this occasion it might be well to trace the progress of some of the developments and practises that have marked the path that the electrical engineer has traversed in the past, with a view of obtaining some idea, possibly, as to whither these paths may lead us in the future. Insofar as this method incorporates a review of the past it presents no particular difficulty; but when it involves a prognostication of what a continuation along any particular line of development will finally lead to, it delves somewhat into the realms of prophecy. I realize full well that anyone who attempts to deal in prophecy among the inventions and developments of this day and age is running a grave risk, and I therefore do not propose to wander far from what I conceive that the trend of present development will carry us toward in the future.

In the matter of efficiency, it has always been recognized that electrical apparatus is in a class by itself. Mechanical energy can be converted into electrical by a generator, or vice versa, by a motor, at an efficiency ranging up to as high as 97 per cent, or even more in the most favorable cases. I think it is a safe statement to say that the average efficiency of the conversion of mechanical energy into electrical by generators, or electrical energy into mechanical by motors, including all sizes under actual operating conditions, will reach 90 per cent. There are, of course, many cases where the efficiencies are lower than 90 per cent. On the other hand, there are many cases where the conversion is carried on at much higher 
efficiencies, and I believe that the assumption of 90 per cent as an average figure is not far from the truth. Owing to the fact that the size of the average electrical generator is much greater than that of the average motor and that it is possible to operate the generator at higher average loads than in the case of the motor, it must be apparent that the average efficiency in converting mechanical energy into electrical energy is higher than in the reconversion of this electrical energy back into mechanical. The average generator efficiency is undoubtedly well above 90 per cent, while it is doubtful if the average motor reaches so high a figure. However, the general conclusion I would draw from these figures is not modified by this difference between generator and motor. This conclusion, which must be apparent to anyone, is that no development of a revolutionary character can be looked for in this respect. Our ability to convert mechanical energy into electrical, or vice versa, has reached so high a value that even if we could obtain perfection itself we could add only a matter of 10 per cent to what we have already accomplished. This conclusion must hold unless the law of conservation of energy is revoked, and I am not predicting any suspension of that law.

When we come to deal with the efficiencies by which electrical energy in one form is transformed into electrical energy of another form, efficiencies are found to be still higher. The efficiencies of some of our larger transformers, for instance, exceed 99 per cent. The synchronous converter, in which alternating current is changed into direct, attains efficiencies approaching 98 per cent. It is evident that perfection itself could not add greatly to existing performances and hence nothing revolutionary may be expected along this line in the future.

When we come to consider the prime mover, we find a marvelous improvement in recent years. Taking up first the waterwheel, the early attempts to develop power at Niagara Falls constitute a significant commentary upon the status of the waterwheel at that time (the late 60 's and the early 70 's). About that time the building of what is now known as the Schoellkopf canal at Niagara Falls made available a head of about $215 \mathrm{ft}$. at the edge of the cliff below the falls on the American side. Of this 215 -ft. head, these earliest wheels used only some 15 or $20 \mathrm{ft}$. for some of the least progressive, and from there up to possibly 40 or $50 \mathrm{ft}$. for the more progressive. After passing through the wheels under this head, the water was 
then discharged at the face of the cliff and fell uselessly for the remainder of the distance, much to the detriment of the scenic beauty of the bank. And not only was it impossible at that time to obtain waterwheels that would work under more than these very limited heads, but the efficiencies of such as were used were very far below those attainable now. Today, waterwheels have no limit in head, except that imposed by the strength of available materials, and efficiencies ranging up to 90 per cent are expected as matters of course. Improvements in waterwheel design will, of course, continue, but perfection itself would add but a matter of 10 per cent to the best of our modern practise, and not to exceed 20 per cent to 25 per cent to the worst. Therefore, in waterwheels, as well as in motor and generator practise, we are approaching the limits set by natural laws almost as closely as human ingenuity can be expected to attain. No startling or record-breaking developments need be expected along these lines so long as the law of conservation of energy holds.

In thermodynamic engines too, the last few years have seen marvelous improvement. The reciprocating engine of Watt has largely given place in recent years to the steam turbine, and the use of the turbine has enabled us to attain efficiencies in thermodynamic conversion that were out of the question with the reciprocating engine of Watt. In the thermodynamic conversion the law of conservation of energy takes a peculiar form. No conceivable method of thermodynamic conversion can begin to transform all of the energy contained in a lump of coal, for instance, into dynamic or mechanical form. If the heat contained in the coal is used to heat a fluid and that fluid is used in a thermodynamic engine, the maximum mechanical energy that can be taken from that engine can bear no greater ratio to the total heat imparted by the fuel to the fluid than the actual range of temperature used in the engine does to the maximum absolute temperature of the fluid as it enters the engine. The efficiency which would result by the use of this ratio of temperature ranges is that which would result if what is known as the "Rankine cycle efficiency" were 100 per cent. Some of the best of our modern steam turbines have attained to as high as 75 per cent-or possibly a little more-of this Rankine cycle efficiency. In these most perfect engines, therefore, perfection itself would not add more than 25 per cent or such a matter. It should be particularly borne in mind that this 
statement is true only of the best of modern practise. It is not true that the average of modern practise attains anywhere near this degree of perfection. It is only with prime movers of the largest size and most modern design and construction that so close an approach to the ideal can be attained. As capacity is reduced it becomes rapidly more and more difficult to attain the higher degrees of economy in thermodynamic machines. This must always remain one of the potent factors in the economics of power supply. It is, and undoubtedly always will be, one of the fundamental reasons why central station supply of electric service must prevail as against isolated plant supply for the same service. The central station can, of course, use units which are very large in comparison, and can be worked at much higher average loads than must necessarily be the case with an isolated plant.

One obvious means that has been suggested to improve the efficiency of the thermodynamic engine is to increase the temperature range through which the working fluid is used. When using water or steam as the fluid in our heat engine, there are certain practical limitations to the temperature range which is available and the temperature range cannot be materially extended over the best of modern practise. The only two ways to extend this temperature range when using steam are to increase the superheat or increase the pressure. Increasing the superheat over the best modern practise does not promise results commensurate with the expenditure of heat to obtain this superheat, since increasing the temperature at one end of the heat cycle simply involves a loss in the efficiency at the other end. There is a rather definite limit to superheating of steam beyond which it is useless to go. Increasing the steam pressure does promise results, and it is probable that the tendencies for the future developments in thermodynamic engines will be toward these higher steam pressures.

Another promising method of increasing temperature range is that to which attention has been called during the last year or two by Mr. W. L. R. Emmet of Schenectady. He has called attention to the advantages of using mercury as the working fluid in a heat engine for temperature ranges above those available with steam. After working the mercury through a given temperature range, the heat remaining in the mercury is transferred to water and the steam thus made available is again worked through a lower temperature range. The ad- 
vantages of this are that the steam is in practically all respects the same as in standard steam turbine practise and the mercury cycle is closely similar to the steam. Additional energy is made available from the same amount of initial heat, due to the greater temperature range obtainable by the use of the mercury. The main disadvantage is the poisonous nature of mercury vapor and the difficulty of absolutely preventing its leakage at the high pressures and temperatures of the mercury boiler. These practical difficulties make it too early to predict whether or not this method will work out as a feasible solution of the thermodynamic engine problem. However, it can be said that without some such method or device, the future is apt to bring no revolutionary improvements in thermodynamic engines over the best of modern practise. Improvements of course will undoubtedly continue to take place, but it cannot be hoped that the improvements of the future will be of the same revolutionary character as the improvements in the thermodynamic engine which have taken place within the last 10 or 15 years. Here again we are approaching so close to the law of conservation of energy that it is safe to make a prediction of this nature.

In the matter of size and capacity of generating units, it can safely be said that this is a consideration that will hereafter be fixed by the conditions to be met and not by any inherent limitation in our ability to produce units of any desired output. We now have units of $30,000 \mathrm{kw}$. capacity in service and still larger ones projected, and no limitations of design or material appear of such a nature as to place a stop to further progress along the same line.

At Omaha, in June 1898, the then president of our Institute, Dr. A. E. Kennelly, made an inaugural address upon the topic, "The Present Status of Electrical Engineering." This address constitutes a very convenient milestone by which to judge our progress since that time, and in this address I will take the liberty of quoting freely from this 1898 address of Past President Kennelly. In the matter of generator sizes, he says, "In 1884 a 50-kw. dynamo was considered a large machine, while a $100-\mathrm{kw}$. Edison steam dynamo was justly called a 'jumbo'. At present the largest size of generator built or building is of $4600-\mathrm{kw}$. capacity." In the 14 years from 1884 to 1898 the maximum size of generator therefore increased 46 fold, while in the 17 years since that time, the increase has only been a bout seven-fold. While the increase in capacity therefore 
has been a marked one, the rate of increase has not been so rapid during the last 17 years as it was in the previous 14 years, a result which naturally might have been anticipated. The future will undoubtedly continue to produce larger and larger capacity machines, the limit as to size being dictated by plant capacity and economic considerations and not by any inability to produce the larger sizes.

In the matter of selling price of such apparatus the following extract from Kennelly in 1898 may be of interest: "The price of dynamos in 1882 was about 20 cents per watt of output, while dynamos of similar running speed for comparatively small sizes without switchboards now cost about 2 cents per watt." The speed and size of these units is not mentioned, but it may be said in comparison that nowadays prices are frequently quoted below one-half cent per watt. In this respect again, the improvement in the last 17 years has not been so marked as it was in the 14 years previous, a result that is only to be expected. In the next succeeding period it is probable that a still smaller degree of improvement will occur. We are approaching a saturation point in this respect.

It may be well to point out some of the reasons for this approach to saturation in the matter of costs. The two fundamental costs of electrical apparatus are those of labor and material. In regard to the item of labor, I submit that it is safe to predict that the tendency for the future will be for the cost of labor to increase rather than decrease. Economies in the use of labor will undoubtedly take place by the introduction of the methods of scientific management, etc., but these need not be expected to be revolutionary in character so far as cost of apparatus is concerned. The tendency of the labor item will unquestionably be toward appreciation rather than depreciation.

In regard to the item of material, modern design has approached very close to the physical limits of available materials. Take, for instance, the property of permeability possessed by irons. With higher permeability, making available greater flux densities, the cost of electrical apparatus might be considerably reduced. That the future will bring some improvement in this respect is unquestionable; but it is further highly improbable that this improvement will be of such a revolutionary character as to cause any sweeping change in the cost of electrical apparatus. 
The hysteresis and eddy current losses that take place in irons and steels that are subjected to varying magnetic fluxes constitute another of the limits encountered in the design of electrical machines. Marked progress has been made in this respect in recent years. Our modern transformer steels in the matters of losses and iron aging qualities show a vast improvement over those formerly available. Unfortunately, these improvements have so far been accompanied by a decrease in permeability which is highly objectionable, particularly in rotating machinery. Unquestionably, further improvements will be made in the magnetic qualities of our irons and steels, but these improvements will probably make no revolutionary change in the costs of electrical apparatus.

The conductivity of copper and other metals is another physical property that sets a limit to the output and cost of our electrical apparatus. Apparently we have reached a definite limit in this respect. The conductivity of the copper of commerce is within an extremely small percentage of that of pure copper and we cannot expect to obtain a higher conductivity in copper than that of purity. There remains, of course, the possibility of using some metal other than copper, but at this present time there is very little promise in that possibility. There is apparently no metal that even approaches the space and cost characteristic of copper that makes it so essential to the construction of electrical apparatus. Aluminum is a competitor only when the volume of the conductor is not an essential element in design, as a transmission line and the like.

One of the most pressing of our existing limitations to a reduction in cost of electrical apparatus is that fixed by temperature rise. The output of a piece of electrical apparatus increases with the temperature rise, and the temperature rise in turn is dictated by the point of balance between the rate at which heat is put in and that at which it is taken out of a machine. The rate at which heat is put in depends largely upon such physical characteristics as hysteresis and permeability of iron and conductivity of copper, which characteristics are already being crowded to the limit by our modern designs. The rate at which heat is dissipated depends upon the efficacy of the ventilation methods used, and in this particular there is a considerable opportunity for improvement. The methods and devices for taking heat out of machines are just as important, when con- 
sidering temperature rise, as the prevention of heat from entering. While there is unquestionably room for considerable improvement in this particular, there is a question as to whether it will cause any material reduction in the cost of such apparatus. The additional cost of applying the more efficient methods of dissipating heat will go far toward nullifying their tendency toward a reduction of cost.

However, there is one line of development that does promise some reduction in cost, and that is the tendency toward higher operating temperatures. In the past, the maximum operating temperature has been fixed by the disintegrating point of fibrous insulation, and this point has placed a very definite and logical limit to temperature rises in such machines. However, when types of insulation are used which do not have this definite temperature of disintegration, this reason for such a temperature limit disappears. Just how far we can go in apparatus temperatures without exceeding the safe limits of these heatresisting insulations is as yet problematical. However, a limit to an indefinite extension in this direction is set by the temperature coefficient of copper conductors, the property that causes the resistance to rise with increasing temperature, thereby causing still higher losses and in turn still higher temperatures. If we go high enough, we will reach a point of unstable equilibrium in this temperature rise curve, where the apparatus will literally and automatically "burn out." This point is, of course, far above anything that is projected at the present time, but while we are looking for limits, we might as well recognize that such a one exists.

In the matter of power production therefore, although we have steadily improved in the past, both as to costs and as to performance, and although we may expect to continue this steady improvement in the future, we must not expect that these improvements will be of the same revolutionary character as they have been in the past. We can see ahead of us a definite limit beyond which it will be impossible to improve the methods of power production now in use. I do not mean to say that there will be no new or revolutionary methods developed in the future, but so long as we continue to get our power from falling streams and burning coal, we need not expect to see the same radical improvements in the future as have distinguished the past. To illustrate my point more fully, let us consider the nature of a water power. Water is evaporated by the 
action of the sun and is carried miles above the earth into the clouds. Here it is precipitated in the form of rain or snow and falls on the earth. The streams carry this water back to the ocean and it is then ready to repeat the cycle. Our existing water powers utilize an almost infinitesimally small part of this water over an almost infinitesimally small part of the total height to which the sun carried it. Insofar as is concerned the water we use over the head through which we use it, we do fairly well, but the part of the sun's energy which we thereby realize is so infinitesimally small that it puts us to shame. Some Westinghouse or Edison of the future will show us how to use the sun's energy directly. The point I wish to make is that the revolutionary improvements in power production methods of the future must come in a fundamental change of method rather than in the continued improvement of existing methods.

So much, then, for the methods of producing power. In the matter of utilization of power a few comparisons $w$ ith the past may not be amiss. As indicated early in this address, the modern motor has reached a stage, insofar as efficiency is concerned, such that little improvement may be expected. We are within a comparatively small percentage of perfection in this respect. The progress of the future will undoubtedly come from improvements in methods of application, and in this direction the field is inexhaustible. For instance, the problem of applying electrically the large amounts of power which are demanded by our modern railroad trains has not yet received a solution which is satisfactory to all concerned. That the problem will be solved there is no doubt in my mind, but just how, is a question that I do not propose to discuss in this address. However, this is only one of the many problems that confront the electrical engineer. The devising of methods for the application of electricity to our modern industries constitutes the occupation of no small part of our fraternity; as witness the many pages in our Procendings that have been. occupied during the past years by the activities of the Industrial Power Committee. It is along this line that we may expect much of what the future may have to offer us of a revolutionary character.

In the field of electric lighting there have been developments of importance. After the telegraph, in point of time, the electric light was the first practical application of electricity.

Most of our modern development in electrical engineering 
has taken its initiative from the supply of electric lighting to our communities. In this matter of electric lighting let me quote again from Kennelly's 1898 address: He says, "The price of a 16-candle power incandescent lamp 16 years ago was about $\$ 1.00$. Now it is about 18 cents. The best lamps at that time, under laboratory conditions, gave about 0.28 mean horizontal normal British candle power per watt, and under commercial conditions about 0.20 . The highest pressure for which they could then be obtained was about 110 volts. At the present time, lamps are obtainable giving normally 0.4 mean horizontal British candle power per watt, while under commercial conditions the average lamp normally develops about 0.25 candle per watt. They can also be obtained (at 0.25 candle per watt) for pressures up to 240 volts, and are frequently installed on 220 -volt mains."

Kennelly therefore records an improvement in 16 years of about 50 per cent in cost of lamps to the consumer and about 50 per cent in efficiency. The introduction of the metal filament lamp has enabled us today to record a much greater rate of improvement in efficiency than Kennelly did. He reported an improvement of about 50 per cent in efficiency in the 16 years previous to 1898 . In the 17 years since Kennelly wrote, we have improved our maximum efficiency about 1000 per cent, an advance which is truly marvelous. But here is a field where we have a long way to go yet without reaching a possible limit. It is true that the melting point of the now available materials seems to place the limit of lamp efficiency at a point not much higher than that which we have at present. However, when we come to compare the efficiencies of even our best lamps with that attained by the fire-fly it is evident that we still have a long way to go before we have reached perfection.

In the matter of power transmission, progress during the past few years has been remarkable. In 1898 the record reads:"The electric transmission of the power of falling water is a branch of engineering that has come into service since 1884, and is making rapid strides, owing to the recent successful employment of high voltages and multiphase alternating currents. It has been estimated that about $150,000 \mathrm{kw}$. of this class of machinery is installed on the North American continent, commercially transmitting power to various distances up to 85 miles, at various pressures up to 40,000 volts." Since Kennelly wrote, 17 years ago, the maximum transmission volt- 
ages have gone up about $3 \frac{3}{4}$ times; the maximum then was 40,000 and now is 150,000 volts. The maximum distance of transmission has gone up about $3 \frac{1}{2}$ times, 245 miles as against 85 , and the installed capacity of water power plants on the North American continent about 9 times, 1,350,000 instead of $150,000 \mathrm{kw}$. Kennelly also mentions in his record that "insulation testing sets have been made for producing alternating pressures up to 160,000 volts effective." In this respect we can go at least 10 times better than he reported, $1,000,000$ volts from transformers having been made available on more than one occasion, and in some cases the voltage available from transformers has been pushed even higher. This matter of power transmission is a branch of our industry wherein the progress of the last 17 years since Kennelly made his record has advanced with probably greater rapidity than in any other branch. I feel very sure that the president of our Institute who comes along 17 years hence and compares the then conditions with my record will not be able to claim any such advance as that we now may claim over 1898 . This follows because we are approaching some fairly well defined limits in these matters. For instance, in the question of increasing transmission voltages we are close to the corona limit. The appearance of corona in the transmission line means the continual loss of power and therefore corona cannot be tolerated to any appreciable degree. There are, of course, methods of increasing the voltage range somewhat before corona is produced, such as increasing conductor diameter, but it can be readily seen that the limits of such remedies will be reached long before transmission voltages have increased by the same ratio as they have in the past 17 years.

Another limit that we are approaching in the matter of power transmission is the economic one. Transmitted power cos's more than that generated at the point of delivery on account of the cost of and the losses in the transmission line. There obviously is a limit to the investment that can be made in transmission lines and still be able to supply power with the same economy as it can be generated upon the ground. This consideration, coupled with the rapid advance in methods of generating power from steam, has in my mind placed an economic limit to the transmission of water power so that we cannot expect any such advances in the future as the past 10 or 15 years have given us. That there will continue to be 
improvement and advance, no one can doubt, but its rate will certainly be diminished.

Transmission by high-voltage direct current has received some attention of recent years. While there is no question but that the problems of pure transmission are much simplified by the use of direct current, the accompanying problems of the generation and utilization are so much intensified that nothing is to be gained in this manner. I would predict no material advance for the future in direct-current transmission of power unless some means, as yet undeveloped, is found by which its generation and utilization are made easier and safer than is possible at present.

And so we might go on indefinitely and draw comparisons with past practises. Always we find progress, always also we find that the rate of progress is not so high now as it was in previous years. This is but the working out of a natural law. Electricity is no longer the infant that it was formerly pictured, and cannot be expected to continue the rate of growth of the infant. It is attaining the vigor and strength of manhood. It is contrary to natural law that either a child or an industry can have rapidity of growth and at the same time strength and stability of character. Unquestionably the rapidity of our development is not so great now as it was when Kennelly spoke in 1898 , and in this respect we are but following a natural law. At the same time, our vocation is acquiring a stability and permanence that are absolutely incompatible with the rate of growth that characterized its earlier years. 